\title{
Brain and Whole-Body Imaging of Nociceptin/Orphanin FQ Peptide Receptor in Humans Using the PET Ligand ${ }^{11}$ C-NOP-1A
}

\author{
Talakad G. Lohith ${ }^{1}$, Sami S. Zoghbi ${ }^{1}$, Cheryl L. Morse ${ }^{1}$, Maria F. Araneta ${ }^{1}$, Vanessa N. Barth ${ }^{2}$, Nancy A. Goebl ${ }^{2}$, \\ Johannes T. Tauscher ${ }^{2}$, Victor W. Pike ${ }^{1}$, Robert B. Innis ${ }^{1}$, and Masahiro Fujita ${ }^{1}$ \\ ${ }^{I}$ Molecular Imaging Branch, National Institute of Mental Health, National Institutes of Health, Bethesda, Maryland; \\ and ${ }^{2}$ Eli Lilly \& Co., Indianapolis, Indiana
}

Nociceptin/orphanin FQ peptide (NOP) receptor is a new class of opioid receptor that may play a pathophysiologic role in anxiety and drug abuse and is a potential therapeutic target in these disorders. We previously developed a high-affinity PET ligand, ${ }^{11} \mathrm{C}-\mathrm{NOP}-1 \mathrm{~A}$, which yielded promising results in monkey brain. Here, we assessed the ability of ${ }^{11} \mathrm{C}-\mathrm{NOP}-1 \mathrm{~A}$ to quantify NOP receptors in human brain and estimated its radiation safety profile. Methods: After intravenous injection of ${ }^{11} \mathrm{C}-\mathrm{NOP}-1 \mathrm{~A}, 7$ healthy subjects underwent brain PET for $2 \mathrm{~h}$ and serial sampling of radial arterial blood to measure parent radioligand concentrations. Distribution volume ( $V_{T}$; a measure of receptor density) was determined by compartmental (1- and 2-tissue) and noncompartmental (Logan analysis and Ichise's bilinear analysis [MA1]) methods. A separate group of 9 healthy subjects underwent whole-body PET to estimate whole-body radiation exposure (effective dose). Results: After ${ }^{11} \mathrm{C}-\mathrm{NOP}-1 \mathrm{~A}$ injection, the peak concentration of radioactivity in brain was high $(\sim 5-7$ standardized uptake values), occurred early ( $\sim 10 \mathrm{~min})$, and then washed out quickly. The unconstrained 2-tissue-compartment model gave excellent $V_{\mathrm{T}}$ identifiability $(\sim 1.1 \% \mathrm{SE})$ and fitted the data better than a 1-tissue-compartment model. Regional $V_{T}$ values $\left(\mathrm{mL} \cdot \mathrm{cm}^{-3}\right)$ ranged from 10.1 in temporal cortex to 5.6 in cerebellum. $V_{\mathrm{T}}$ was well identified in the initial $70 \mathrm{~min}$ of imaging and remained stable for the remaining 50 min, suggesting that brain radioactivity was most likely parent radioligand, as supported by the fact that all plasma radiometabolites of ${ }^{11} \mathrm{C}-\mathrm{NOP}-1 \mathrm{~A}$ were less lipophilic than the parent radioligand. Voxel-based MA1 $V_{\mathrm{T}}$ values correlated well with results from the 2-tissue-compartment model, showing that parametric methods can be used to compare populations. Whole-body scans showed radioactivity in brain and in peripheral organs expressing NOP receptors, such as heart, pancreas, and spleen. ${ }^{11} \mathrm{C}-\mathrm{NOP}-1 \mathrm{~A}$ was significantly metabolized and excreted via the hepatobiliary route. Gallbladder had the highest radiation exposure $(21 \mu \mathrm{Sv} / \mathrm{MBq})$, and the effective dose was $4.3 \mu \mathrm{Sv} / \mathrm{MBq}$. Conclusion: ${ }^{11} \mathrm{C}-\mathrm{NOP}-1 \mathrm{~A}$ is a promising radioligand that reliably quantifies NOP receptors in human brain. The effective dose in humans is low and similar to that of other ${ }^{11} \mathrm{C}$ labeled radioligands, allowing multiple scans in 1 subject.

Received Aug. 18, 2011; revision accepted Nov. 3, 2011.

For correspondence contact: Robert B. Innis, Molecular Imaging Branch, National Institute of Mental Health, 10 Center Dr., Bethesda, MD 20892-1026. E-mail: robert.innis@nih.gov

Published online Feb. 6, 2012.

COPYRIGHT @ 2012 by the Society of Nuclear Medicine, Inc.
Key Words: NOP receptors; nociceptin; opioid receptor; PET; receptor imaging

J Nucl Med 2012; 53:385-392

DOI: 10.2967/jnumed.111.097162

$\mathbf{T}$ he nociceptin/orphanin FQ peptide (NOP) receptor was cloned as an orphan receptor with no known endogenous transmitter (1). Subsequently, NOP itself was discovered as a 17-amino-acid peptide with sequence similarities to endogenous opioid peptide dynorphin A (2). The NOP receptor is coupled to the G-protein $\mathrm{G}_{\mathrm{i}} / \mathrm{G}_{\mathrm{o}}$, inhibits the production of cyclic adenosine monophosphate, activates potassium channels, and inhibits calcium channels. Although the NOP receptor shares some amino acid sequence similarities with the classic opiate receptor, the mechanism of action of the NOP transmitter could not be blocked by the opioid antagonist naloxone; thus, the NOP receptor is considered a nonopiate member of the opioid receptor family (3).

NOP receptors are widely distributed in brain, spinal cord, heart, lungs, kidneys, intestine, and immune cells of different mammalian species, where they mediate the actions of endogenous peptides in a complex manner. For example, animal studies suggest that NOP receptor activation in the periphery reduces pain perception, but similar activation in the brain increases pain perception (3). In addition, NOP receptors may mediate both the consumption of alcohol and anxiety-related behaviors. Elevated NOP receptor messenger RNA levels, as well as increased ${ }^{3} \mathrm{H}$-nociceptin binding in central amygdala, were both noted in Marchigian Sardinian alcohol-preferring rats (4). NOP receptor agonists were also shown to have an anxiolytic effect across multiple species (5). As a result, investigators have focused on developing NOP receptor ligands for therapeutic trials in humans.

PET radioligands would be useful for exploring the roles that NOP receptors may play in human health and disease where relevant animal models showed changes. In addition, an NOP receptor radioligand could help determine the therapeutic mechanisms of some opiates; buprenorphine, for 
example, is used to treat both pain and heroin dependence and may act on NOP and other opiate receptors (6). Finally, a PET radioligand for the NOP receptor would aid in the early evaluation of potential therapeutic NOP receptor agonists and antagonists. Such early studies could determine receptor occupancy and clarify required dose and dosing intervals, which are often critically important for the development of drugs that may have restricted access to brain because of the blood-brain barrier and efflux transporters.

Our laboratory developed ${ }^{11} \mathrm{C}-\mathrm{NOP}-1 \mathrm{~A}$, which is to our knowledge the first successful radioligand to image NOP receptors in rat and monkey brain (7). ${ }^{11} \mathrm{C}-\mathrm{NOP}-1 \mathrm{~A}$ is a selective antagonist at the NOP receptor and has high affinity and appropriate lipophilicity for blood-brain barrier permeability. ${ }^{11} \mathrm{C}-\mathrm{NOP}-1 \mathrm{~A}$ imaging in rhesus monkeys showed high brain uptake and a large receptor-specific signal and could be quantified with the gold standard method of compartmental modeling (8).

The present study sought to determine whether ${ }^{11} \mathrm{C}-\mathrm{NOP}-$ $1 \mathrm{~A}$ could image and quantify NOP receptor distribution in the living human brain at a dose safe for human subjects. To evaluate how well uptake could be quantified relative to the amount of radioligand delivered to the brain, we imaged the brain and measured serial arterial blood samples after injecting ${ }^{11} \mathrm{C}-\mathrm{NOP}-1 \mathrm{~A}$. We further imaged the whole body to measure radioactivity in identifiable organs and to estimate radiation exposure to the whole body.

\section{MATERIALS AND METHODS}

\section{Radioligand Preparation}

${ }^{11} \mathrm{C}$-NOP-1A was labeled by ${ }^{11} \mathrm{C}$-methylation of an $\mathrm{N}$-desmethyl precursor, as previously described (7). The radioligand was prepared according to our exploratory Investigational New Drug Application (109077), which has been submitted to the U.S. Food and Drug Administration and a copy of which is available at http://pdsp.med.unc.edu/snidd/IND/nopla.html. The radioligand was obtained with high radiochemical purity ( $>99 \%)$ and a specific activity of $213 \pm 100 \mathrm{GBq} / \mu \mathrm{mol}$ at the time of injection ( $n=16$ batches).

\section{Subjects}

Seven healthy volunteers participated in the brain PET scans (4 men and 3 women; $33 \pm 7$ y old). Nine separate healthy volunteers participated in the whole-body PET scans (5 men and 4 women; $31 \pm 9 \mathrm{y}$ old). All subjects were free of current medical or psychiatric illnesses, as determined by medical history, physical examination, electrocardiogram, urinalysis including drug screening, and laboratory blood tests (complete blood count, serum chemistries, and thyroid function test). Each subject's vital signs were recorded before ${ }^{11} \mathrm{C}-\mathrm{NOP}-1 \mathrm{~A}$ injection and at $15,30,90$, and $120 \mathrm{~min}$ after injection. Urinalysis and blood tests were repeated within $2 \mathrm{~h}$ of PET scan completion.

\section{Measurement of ${ }^{11} \mathrm{C}-\mathrm{NOP}-1 \mathrm{~A}$ in Plasma}

To determine arterial input function for brain PET scans, blood samples $(1.5 \mathrm{~mL}$ each) were drawn from the radial artery at 15 -s intervals until $150 \mathrm{~s}$, followed by 3 -mL samples at 3, 4, 6, 8, 10, $15,20,30,40$, and $50 \mathrm{~min}$, and $5-\mathrm{mL}$ samples at $60,75,90$, and
$120 \mathrm{~min}$. The concentration of parent radioligand was measured as previously described (7).

A metabolite-corrected plasma input function was obtained as follows: the time-activity curves of total radioactivity in plasma and whole blood were fitted to a triexponential function with Poisson weighting of the actual radioactivity counts detected in plasma and whole blood, respectively. The ${ }^{11} \mathrm{C}-\mathrm{NOP}-1 \mathrm{~A}$ parent fraction measured in the plasma samples was fitted to a Hill function with Poisson weighting of the area under the curve of parent peaks from the radiochromatogram. The fitted total plasma radioactivity was multiplied by the Hill function-fitted parent fraction to obtain the metabolite-corrected plasma input function.

The plasma free fraction was measured by ultrafiltration, as previously described (9). Radioactivity in whole blood was used to correct radioactivity in brain that represents the vascular compartment ( $\sim 5 \%$ of tissue volume). All plasma data are mean $\pm \mathrm{SD}$ from 7 healthy subjects.

\section{PET Scans}

All PET scans were performed on an Advance tomograph (GE Healthcare). For brain scans, ${ }^{11} \mathrm{C}-\mathrm{NOP}-1 \mathrm{~A}(716 \pm 83 \mathrm{MBq})$ was intravenously injected over $1 \mathrm{~min}$ and dynamic 3-dimensional emission scans were acquired for $120 \mathrm{~min}$ in 33 frames of increasing duration from $30 \mathrm{~s}$ to $5 \mathrm{~min}$. One brain transmission scan using ${ }^{68} \mathrm{Ge}$ rods was acquired before the injection of the radioligand. Head movement was corrected after the scan by realigning all frames from each subject using Statistical Parametric Mapping (SPM, version 8 for Windows; Wellcome Department of Cognitive Neurology). The position of the transmission scan was corrected for motion before attenuation correction was applied. For whole-body scans, ${ }^{11} \mathrm{C}-\mathrm{NOP}-1 \mathrm{~A}(675 \pm 187 \mathrm{MBq})$ was intravenously injected over $20 \mathrm{~s}$ and dynamic 2-dimensional emission scans were acquired for approximately $120 \mathrm{~min}$ in 14 frames by serial imaging of the body in 7 contiguous segments. The frame duration and transmission scans were conducted as previously described (10).

\section{Brain Image Analysis}

The averaged PET image was created by averaging all frames of the PET images. The averaged PET image was then coregistered to each subject's MR image using a 6-parameter algorithm in SPM. Sagittal MR images of 1-mm contiguous slices were obtained using a 3.0-T Achieva device (Philips Health Care) with a repetition time of $8.1 \mathrm{~ms}$, an echo time of $3.7 \mathrm{~ms}$, and a flip angle of $8^{\circ}$. All MR and PET images were then spatially normalized to Montreal Neurologic Institute space using transformation parameters from the MR images. A template of preset volumes of interest (VOIs) (11) was applied to the spatially normalized PET images to extract time-activity curves for the following 10 regions: frontal $\left(432 \mathrm{~cm}^{3}\right)$, parietal $\left(247 \mathrm{~cm}^{3}\right)$, occipital $\left(172 \mathrm{~cm}^{3}\right)$, temporal $\left(251 \mathrm{~cm}^{3}\right)$, and medial temporal (36 $\left.\mathrm{cm}^{3}\right)$ cortices; caudate $\left(16 \mathrm{~cm}^{3}\right)$; putamen $\left(17 \mathrm{~cm}^{3}\right)$; cingulate $(28$ $\left.\mathrm{cm}^{3}\right)$; thalamus $\left(17 \mathrm{~cm}^{3}\right)$; and cerebellum $\left(195 \mathrm{~cm}^{3}\right)$. Image and kinetic analyses were performed using pixelwise modeling software (PMOD, version 3.16; PMOD Technologies Ltd.).

\section{Calculation of Distribution Volume $\left(V_{T}\right)$}

$V_{\mathrm{T}}$ is an index of receptor density and equals the ratio at equilibrium of the concentration of radioligand in tissue to that in plasma. The concentration of radioligand in tissue represents the sum of specific binding (receptor-bound) and nondisplaceable uptake (nonspecifically bound and free radioligand in tissue water) (12). The equilibrium value of $V_{\mathrm{T}}$ was calculated 3 different ways to assess whether the methods applicable to voxel data yielded $V_{\mathrm{T}}$ 
values similar to those obtained by the VOI data using the gold standard method of compartmental modeling.

Compartmental Modeling. Brain time-activity data were analyzed with both 1- and 2-tissue-compartment models. Rate constants $\left(K_{1}, k_{2}, k_{3}\right.$, and $\left.k_{4}\right)$ in standard 1- and 2-tissue-compartment models were estimated with the weighted least-squares method and the Marquardt optimizer. Brain data for each frame were weighted by assuming that the SD of the data was proportional to the inverse square root of noise equivalent counts. To correct the brain data for the vascular component, radioactivity in serial whole blood was measured and subtracted from the PET measurements, assuming that cerebral blood volume is $5 \%$ of total brain volume. The delay between the arrival of ${ }^{11} \mathrm{C}-\mathrm{NOP}-1 \mathrm{~A}$ in the radial artery and brain was estimated by fitting the whole brain, excluding the white matter.

Linear and Multilinear Graphical Analyses. The graphical approach of Logan (13), a linear regression method with input function that does not specify a particular compartmental configuration, was used to calculate $V_{\mathrm{T}}$. With the maximum deviation between the regression and all measurements set to $20 \%$, the equilibration start time and the slope of the linear portion of the Logan plot $\left(V_{\mathrm{T}}\right)$ were fitted for each brain region that included data from multiple voxels within a VOI. To decrease the bias induced by noise in the measurements, $V_{\mathrm{T}}$ was also calculated by Ichise's bilinear analysis, MA1 (14), using the same start time as that obtained from the Logan analysis for each brain region that included data from multiple voxels within a VOI.

Parametric Imaging. To determine whether $V_{\mathrm{T}}$ could be determined from the voxel data, voxelwise parametric images of $V_{\mathrm{T}}$ $\left(\operatorname{Logan}_{\text {voxel }}\right.$ and $\left.M A 1_{\text {voxel }}\right)$ were generated using data from each voxel of dynamic PET images. For both Logan and MA1 methods, PET frames used for the regression were selected on the basis of start time obtained from the time-activity curve of whole brain excluding white matter and by setting the maximum deviation between the regression and all measurements to $20 \%$. The same plasma input function as that used for compartmental modeling was used for the parametric modeling.

\section{Time Stability Analysis}

To determine the minimal scan length for reliable measurements and to indirectly assess whether ${ }^{11} \mathrm{C}-\mathrm{NOP}-1 \mathrm{~A}$ radiometabolites enter brain, time stability of $V_{\mathrm{T}}$ was examined by increasingly truncating the scan duration from $0-120 \mathrm{~min}$ to $0-40 \mathrm{~min}$ in $10-\mathrm{min}$ increments.

\section{Dosimetry Analysis}

Source organs were identified on the individual transaxial slices of whole-body PET images. The frames with the highest organ uptakes were averaged and smoothed by a gaussian filter to increase the contrast between the organ and surrounding tissue. Brain, lungs, heart, liver, kidneys, gallbladder, urinary bladder, pancreas, and thyroid were identified as the source organs.

Uptake in each source organ was corrected for recovery of measured activity, which was calculated by averaging the activity of the second through sixth frames with a large region of interest placed over the entire body visible by PET. Recovery averaged $87 \% \pm 4 \%$ for all subjects $(n=9)$.

At each time point, the measured activity (i.e., not corrected for decay) of the source organ was expressed as percentage injected activity (\%IA). The area under the time-activity curve of each organ was calculated by the trapezoidal method until scan acquisition ended. The area after the last image to infinity was calculated by assuming that the subsequent decline of radioactivity occurred by only physical decay, without any further biologic clearance. The area under the curve of \%IA from time zero to infinity equals the residence time of the organ. To calculate the residence time for the remainder of the body, the residence times for all source organs were summed and subtracted from the fixed theoretic value of half-life/ln2 $=0.49 \mathrm{~h}$.

Radiation absorbed doses were calculated according to the MIRD scheme using OLINDA/EXM 1.1 (http://www.doseinforadar.com/OLINDA.html) using the model for a 70-kg adult male.

\section{Statistical Analysis}

The optimal compartment model (i.e., 1 vs. 2 tissue compartments) was chosen on the basis of the Akaike information criterion, model selection criterion, and $F$ test (15). The most appropriate model would be the one with the smallest Akaike information criterion and the largest model selection criterion value. $F$ statistics were used to compare goodness of fit by 1- and 2-tissue-compartment models. A value of $P$ less than 0.05 was considered significant. The identifiability of $V_{\mathrm{T}}$ was expressed as a percentage and equaled the ratio of the SE of $V_{\mathrm{T}}$ divided by the value of $V_{\mathrm{T}}$ itself. A lower percentage indicates better identifiability.

For each subject, using simple regression we compared regional brain $V_{\mathrm{T}}$ values by Logan and MA1 methods obtained from VOI and voxel data, and the $V_{\mathrm{T}}$ values obtained from the gold standard method of 2-tissue-compartment model applied to VOI data. To compare the difference in $V_{\mathrm{T}}$ between different methods, we applied repeated-measures ANOVA for $V_{\mathrm{T}}$ values in the regions. All statistical analyses were performed with SPSS (version 17 for Windows; SPSS Inc.). Group data are expressed as mean \pm SD. The mean and SD for parametric images were calculated in each voxel across subjects, and then values from all voxels were averaged within each VOI.

\section{RESULTS}

\section{Pharmacologic Effects}

The injected mass dose of ${ }^{11} \mathrm{C}-\mathrm{NOP}-1 \mathrm{~A}$ was $53 \pm 36$ $\mathrm{pmol} / \mathrm{kg}(n=16)$. This dose caused no pharmacologic effects in any subject during the 2-h PET scan, nor did it affect blood pressure, pulse, respiratory rate, electrocardiogram, or pulse oximetry. Similarly, no significant effects were noted in any of the blood or urine tests acquired at the end of the scan.

\section{Plasma Analysis}

${ }^{11} \mathrm{C}-\mathrm{NOP}-1 \mathrm{~A}$ concentrations in arterial plasma peaked to $13 \pm 4$ standardized uptake values (SUVs) at $75 \mathrm{~s}$ after ${ }^{11} \mathrm{C}$ NOP-1A injection and then rapidly declined, followed by a slow terminal clearance phase. The fraction of ${ }^{11} \mathrm{C}-\mathrm{NOP}-$ $1 \mathrm{~A}$, expressed as a percentage of total plasma radioactivity, declined rapidly and reached $52 \% \pm 12 \%$ at $15 \mathrm{~min}$ followed by a gradual decline (Supplemental Fig. 1). The fitting of whole blood and total plasma curves converged by triexponential function, and that of parent fraction curve converged by Hill function in all subjects. Figure 1A shows the measured and fitted parent fraction curves, and Figure 1B shows the parent concentration and fitting in a single subject.

Radiometabolites appeared quickly in the plasma and, after $20 \mathrm{~min}$, became the predominant component of plasma radioactivity. All radiometabolites eluted before the more lipophilic parent but were not well resolved by 


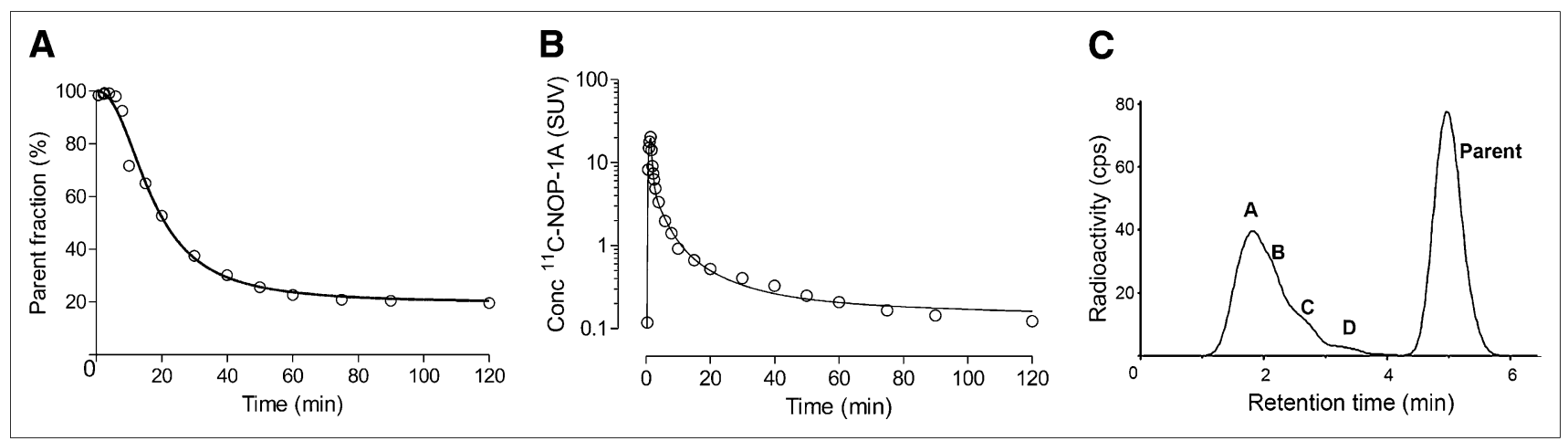

FIGURE 1. Parent radioligand fraction, radioactivity concentrations (conc), and radiometabolite profile in plasma from 40-y-old healthy man injected with $755 \mathrm{MBq}$ of ${ }^{11} \mathrm{C}-\mathrm{NOP}-1 \mathrm{~A}$. (A) Fraction of unchanged parent radioligand ${ }^{11} \mathrm{C}-\mathrm{NOP}-1 \mathrm{~A}(\mathrm{O})$ in plasma fitted by Hill function. (B) Time course of parent ${ }^{11} \mathrm{C}-\mathrm{NOP}-1 \mathrm{~A}$ concentration $(O)$ in arterial plasma fitted by multiplying triexponential-fitted total plasma radioactivity and Hill function-fitted plasma parent fraction. (C) Radiochromatogram illustrating plasma composition 40 min after injection of ${ }^{11} \mathrm{C}-\mathrm{NOP}-1 \mathrm{~A}$. Radioactivity was measured in counts per second (cps). Peaks A to D and parent are labeled with increasing lipophilicity.

reverse-phase high-performance liquid chromatography (Fig. 1C). The parent radioligand eluted at 5 min and was well separated from the rest of the radiometabolites.

The plasma free fraction and clearance of ${ }^{11} \mathrm{C}-\mathrm{NOP}-1 \mathrm{~A}$ were $10.1 \% \pm 1.7 \%(n=7)$ and $1.2 \pm 0.3 \mathrm{~L} / \mathrm{min}(n=7)$, respectively.

\section{Brain Radioactivity and Kinetic Analysis}

After ${ }^{11} \mathrm{C}-\mathrm{NOP}-1 \mathrm{~A}$ injection, all subjects showed high concentrations of radioactivity followed by quick washout in all brain regions. Radioactivity in brain peaked to approximately 5-7 SUVs at about $10 \mathrm{~min}$ and decreased to $50 \%$ of the peak by about 50 min (Supplemental Fig. 2). Consistent with the distribution of ${ }^{3} \mathrm{H}$-nociceptin binding in postmortem human brain (16), the in vivo distribution of radioactivity was widespread in brain, with moderate levels in all areas of neocortex, highest in putamen, and lowest in cerebellum (Fig. 2). Because no brain region lacks NOP expression, we did not apply a reference region method in the kinetic analysis.

The kinetic analysis of brain and plasma data had 4 major results. First, the brain time-activity curves from VOI data fitted better with an unconstrained 2- than a 1-tissue-compartment model. Second, Logan and MA1 analyses using both VOIand voxel-based methods could determine $V_{\mathrm{T}}$ but significantly underestimated it compared with a 2-tissue-compartment model. Third, although the $\mathrm{MA}_{\text {voxel }} V_{\mathrm{T}}$ was significantly lower than the 2-tissue-compartment model $V_{\mathrm{T}}, \mathrm{MA} 1_{\text {voxel }}$ $V_{\mathrm{T}}$ values across regions correlated well with 2-tissue $V_{\mathrm{T}}$ and were significantly higher than $\operatorname{Logan}_{\text {voxel }} V_{\mathrm{T}}$. Fourth, 70-min data adequately measured $V_{\mathrm{T}}$.

With regard to the first result, unconstrained 2-tissuecompartment fitting converged in all regions and in all scans. An $F$ test showed that the 2-tissue-compartment model was superior to the 1-tissue-compartment model in all 60 fittings in a total of 6 scans (Fig. 3), indicating the presence of significant amounts of both specific and nonspecific binding in human brain. In addition, the 2-tissue-compartment model showed lower mean Akaike information criterion scores $(93$ vs. 173) and higher mean model selection criterion scores (7.4 vs. 4.9) than the 1-tissue-compartment model. One scan showed significantly better fit in all regions by 1 - than 2tissue-compartment model as determined by $F$ test, Akaike information criterion, and model selection criterion scores. The unconstrained 2-tissue-compartment model identified $V_{\mathrm{T}}$ with average SE of $1.1 \%$ across brain regions. Regional values of 2-tissue $V_{\mathrm{T}}\left(\mathrm{mL} \cdot \mathrm{cm}^{-3}\right)$ ranged from 10.1 in temporal cortex to 5.6 in cerebellum. The rate constants $K_{1}$ and $k_{2}$ were relatively well identified, with a median SE of less than $10 \%$ across all regions, whereas the rate constants $k_{3}$ and $k_{4}$ were poorly identified, with median SEs of more than $10 \%$ across all regions (Supplemental Table 1).

As regards the second result, $V_{\mathrm{T}}$ was also calculated using the Logan graphical approach (Supplemental Fig. 3) and MA1, as well as voxel-based Logan and MA1 models. The 2-tissue $V_{\mathrm{T}}$ provided the highest estimates of $V_{\mathrm{T}}$ across all brain regions (Table 1). Logan and MA1 models from both

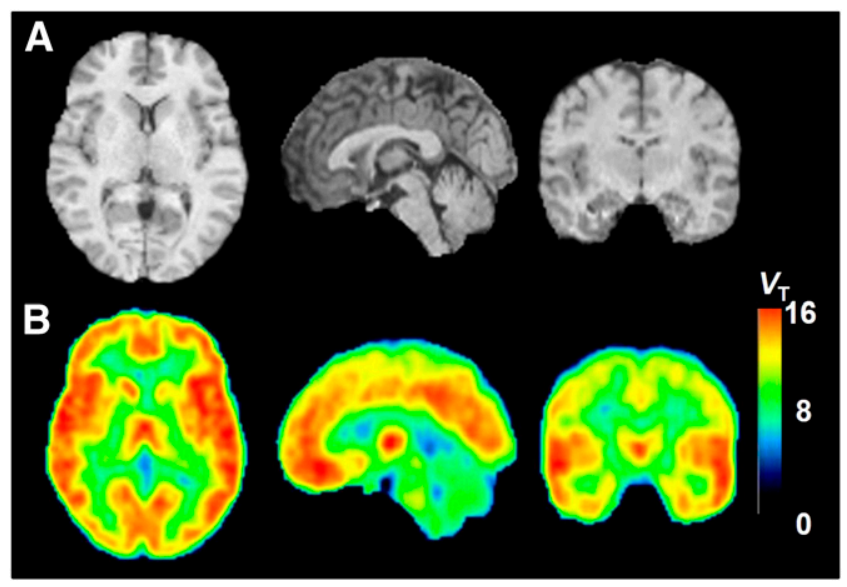

FIGURE 2. MRI and MA1 parametric PET images of 44-y-old healthy man injected with $738 \mathrm{MBq}$ of ${ }^{11} \mathrm{C}-\mathrm{NOP}-1 \mathrm{~A}$ : MRI anatomic images (A) and MA1 parametric images (B) in axial (left), sagittal (middle), and coronal (right) views. Each pixel value represents $V_{\mathrm{T}}$ and is indicated in $V_{T}$ color scale on right. 


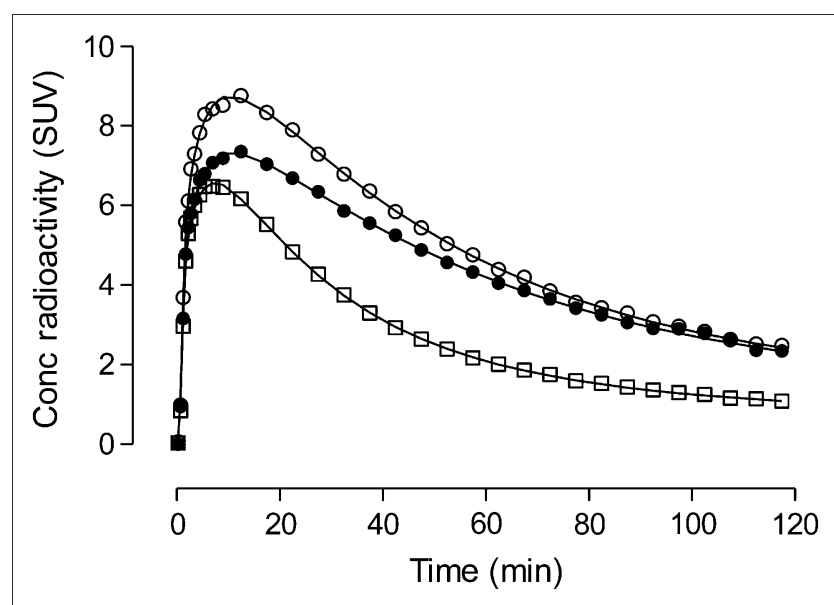

FIGURE 3. Representative brain uptake with compartmental fitting from 40 -y-old healthy man injected with $755 \mathrm{MBq}$ of ${ }^{11} \mathrm{C}$ NOP-1A. Concentration of radioactivity from 3 regions is shown: putamen $(\bigcirc)$, with highest uptake; cingulate cortex $(\mathbf{O})$, with medium uptake; and cerebellum ( $\square$ ), with lowest uptake. Line represents unconstrained 2-tissue-compartment fitting.

VOI- and voxel-based methods significantly (all $P<0.05$ ) underestimated $V_{\mathrm{T}}$ in all subjects (factorial repeated-measures ANOVA using Bonferroni adjustment, $F_{2.35,14.10}=93.11$ ), but intersubject variability was similar among different methods. The mean difference in $V_{\mathrm{T}}$ was highest between 2-tissue and $\operatorname{Logan}_{\text {voxel }}(1.06)$ models. $V_{\mathrm{T}}$ estimated by MA1 voxel was significantly higher $(P<0.05)$ than that estimated by Logan $_{\text {voxel }}$ model, with a mean difference of 0.45 (Fig. 4A).

As regards the third result, $\mathrm{MA} 1_{\text {voxel }} V_{\mathrm{T}}$ significantly correlated with 2-tissue $V_{\mathrm{T}}$ for all subjects (Fig. 4B). The Pearson $R^{2}$ for brain regions without cerebellum ranged from 0.94 to $1.0(P<0.001)$. The nonparametric Spearman $\rho$ for brain regions with cerebellum ranged from 0.89 to $1.0(P<0.001)$. Figure 3 displays parametric images of $V_{\mathrm{T}}\left(\mathrm{MA} 1_{\text {voxel }}\right)$ from a single subject.

Finally, $V_{\mathrm{T}}$ values were stable from 70 to $120 \mathrm{~min}$ and were well identified (SE $<10 \%$ ) using only 70-min data (Supple- mental Fig. 4), indicating negligible accumulation of radiometabolites and suggesting that $70 \mathrm{~min}$ of scan data are adequate to calculate $V_{\mathrm{T}}$.

\section{Whole-Body Biodistribution and Dosimetry Estimates}

Whole-body images were notable for early distribution of radioactivity in the blood pool, accumulation in the target organ (i.e., brain), and excretion via hepatobiliary and urinary routes (Figs. 5 and 6). At early time points, radioactivity was prominent in organs with high blood volume, including heart, kidneys, spleen, and thyroid. Consistent with its high density of NOP receptors, the brain had high radioactivity uptake, with a peak of about $11 \%$ IA at $8-10$ min after ${ }^{11} \mathrm{C}-\mathrm{NOP}-1 \mathrm{~A}$ injection. The images showed that radioactivity was excreted via both hepatobiliary and urinary routes (with about $7 \%$ IA in gallbladder and about $6 \% \mathrm{IA}$ in urinary bladder by the end of the scan). In addition, radioactivity was prominent in heart and pancreas, with a peak of about 1.4 and $1.5 \%$ IA at 8-10 min. The spleen also showed high radioactivity uptake, with a peak of about $2.5 \%$ IA at 2 min.

The 3 source organs with the longest residence time of radioactivity were liver, brain, and lungs (Supplemental Table 2). The 3 organs with the highest estimates of radiation exposure $(\mu \mathrm{Sv} / \mathrm{MBq})$ were gallbladder wall $(21.4 \pm$ $10.1)$, pancreas $(16.3 \pm 7.5)$, and kidneys $(12.2 \pm 1.6)$ (Supplemental Table 3). The effective dose, which is a weighted sum of overall exposure to the organs, was $4.3 \pm$ $0.2 \mu \mathrm{Sv} / \mathrm{MBq}(15.8 \pm 0.9 \mathrm{mrem} / \mathrm{mCi})$.

\section{DISCUSSION}

To our knowledge, this study was the first to investigate the imaging and quantification of NOP receptors in living human brain. Using ${ }^{11} \mathrm{C}-\mathrm{NOP} 1 \mathrm{~A}$, we found that radioactivity uptake in brain was high and stably quantified as total $V_{\mathrm{T}}$, reflecting the density of the receptors. Using metabolite-corrected arterial input function, $V_{\mathrm{T}}$ was well quantified, with high identifiability (i.e., low SE) by the gold standard method of 2-tissue-compartment kinetic modeling.

TABLE 1

Regional $V_{\mathrm{T}}$ of ${ }^{11} \mathrm{C}-\mathrm{NOP}-1 \mathrm{~A}$ in Human Brain Determined from Large VOls or from Individual Voxels

\begin{tabular}{|c|c|c|c|c|c|}
\hline \multirow[b]{3}{*}{ Brain region } & \multicolumn{5}{|c|}{$V_{\mathrm{T}}\left(\mathrm{mL} \mathrm{cm}^{-3}\right)$} \\
\hline & \multicolumn{3}{|c|}{ VOI } & \multicolumn{2}{|c|}{ Voxel } \\
\hline & Two-tissue & Logan $_{\text {vol }}$ & $M A 1_{\text {vol }}$ & Logan $_{\text {voxel }}$ & $M A 1_{\text {voxel }}$ \\
\hline Temporal cortex & $10.1 \pm 1.6$ & $9.6 \pm 1.6$ & $9.5 \pm 1.5$ & $8.9 \pm 1.7$ & $9.4 \pm 1.8$ \\
\hline Cingulate cortex & $9.4 \pm 1.5$ & $8.9 \pm 1.5$ & $8.9 \pm 1.5$ & $8.3 \pm 1.5$ & $8.8 \pm 1.6$ \\
\hline Putamen & $10.0 \pm 1.8$ & $9.5 \pm 1.7$ & $9.4 \pm 1.7$ & $8.9 \pm 1.7$ & $9.3 \pm 1.8$ \\
\hline Thalamus & $9.0 \pm 1.6$ & $8.5 \pm 1.5$ & $8.5 \pm 1.5$ & $8.0 \pm 1.6$ & $8.5 \pm 1.6$ \\
\hline Cerebellum & $5.6 \pm 0.8$ & $5.2 \pm 0.8$ & $5.3 \pm 0.8$ & $4.8 \pm 1.0$ & $5.1 \pm 1.0$ \\
\hline
\end{tabular}

Values are mean \pm SD from 7 humans using 120 min of brain and plasma data. Two-tissue-compartment model was fit with no constraints. Subscript "VOI" denotes that concentration of radioactivity from large VOls (e.g., entire temporal cortex of $\left.251 \mathrm{~cm}^{3}\right)$ was analyzed. Subscript "voxel" denotes that concentration of radioactivity of individual voxel $\left(8 \mathrm{~mm}^{3}\right)$ was analyzed. Voxels of resulting parametric image have values equal to $V_{\mathrm{T}}$. 
FIGURE 4. Comparison of total $V_{\mathrm{T}}$ in various brain regions. $V_{\mathrm{T}}$ values were calculated in 7 subjects injected with ${ }^{11} \mathrm{C}-\mathrm{NOP}-1 \mathrm{~A}$ using unconstrained 2-tissue-compartment model for VOI data and Logan and MA1 methods for voxel data (Logan $_{\text {voxel }}$ and $\left.M A 1_{\text {voxel }}\right)$. (A) Mean $V_{T}$ values obtained by both MA1 $1_{\text {voxel }}$ (hatched bars) and Logan voxel (white bars) were significantly lower than those obtained by 2-tissue-compartment model (black bars) $(P<0.05$ by factorial repeated-measures ANOVA). Logan voxel $_{\text {gave }}$ significantly smaller $V_{\mathrm{T}}$ values than $M A 1_{\text {voxel }}$ $(P<0.05)$. Data represent mean $\pm \mathrm{SD}$ of all 7 subjects. (B) Scatterplot comparing mean $V_{\mathrm{T}}$ values from each region (excluding cerebellum) by MA1 $1_{\text {voxel }}$ method vs. 2-tissue-compartment model in 40 -y-old healthy man injected with 755 MBq of ${ }^{11} \mathrm{C}-\mathrm{NOP}-1 \mathrm{~A}$. Simple linear regression was significant (Pearson $R^{2}=0.95, P<0.0001$ ), with linear regression line equation $y=1.05 x+0.1$. Solid line represents line of best fit. Dashed lines are 95\% confidence intervals. FC = frontal cortex; PA = parietal cortex; OC = occipital cortex; TC = temporal cortex; $\mathrm{MT}=$ medial temporal cortex; $\mathrm{CC}=$ cingulate cortex; $\mathrm{CA}=$ caudate cortex; $\mathrm{PU}=$ putamen; $\mathrm{TH}=$ thalamus; $\mathrm{CE}=\mathrm{cerebellum}$.

$V_{\mathrm{T}}$ determined from the voxel-based MA1 method correlated well with the results from a 2-tissue-compartment model, indicating that parametric methods could be used for quantification in population studies. Whole-body scans of ${ }^{11} \mathrm{C}-\mathrm{NOP}-1 \mathrm{~A}$ showed that the effective dose to humans was $4.3 \mu \mathrm{Sv} / \mathrm{MBq}$, which is similar to the effective dose of other ${ }^{11} \mathrm{C}$-labeled radioligands.

After the discovery of the NOP receptor in 1994 and its endogenous ligand NOP a year later, numerous peptide and nonpeptide ligands targeting the NOP receptor were developed. However, until now, no promising radioligands had been developed capable of imaging NOP receptors in vivo in humans. Two radioligands developed by Ogawa et al. $(17,18)$ - ${ }^{11}$ C-methyl-Ro 64-6198 and ${ }^{11} \mathrm{C}-\mathrm{CPEB}$ - had high affinity for NOP receptors in rat brain, but they also had high nonspecific binding, making them unsuitable for PET. In comparison, initial trials with our radioligand, ${ }^{11} \mathrm{C}-\mathrm{NOP}-1 \mathrm{~A}$, dem- onstrated a selective and displaceable binding with high affinity at NOP receptors in rats and monkeys $(7,8)$.

We found that radioactivity in human brain was high after ${ }^{11} \mathrm{C}-\mathrm{NOP}-1 \mathrm{~A}$ injection, followed by a quick washout from all brain regions. Notably, high uptake and quick washout from brain enable the quantification of brain uptake by compartmental modeling, given that the kinetics of the radioligand reflect association and dissociation binding to the target receptor. Both 1- and 2-tissue-compartment models successfully identified $V_{\mathrm{T}}$ with a low SE. However, statistical analysis showed that the 2-tissue-compartment model provided a significantly better fit in most scans, consistent with both specific and nonspecific compartments in brain. Interestingly, our previous studies of ${ }^{11} \mathrm{C}-\mathrm{NOP}-1 \mathrm{~A}$ in monkey brain had shown that the 1-tissue-compartment model provided a better fit than the 2-tissue model. In addition, $V_{\mathrm{T}}$ values from brain regions were nearly 2 -fold
FIGURE 5. Whole-body images of healthy 22-y-old man show distribution of radioactivity at about 6, 50, and 102 min after injection of $480 \mathrm{MBq}$ of ${ }^{11} \mathrm{C}-\mathrm{NOP}-1 \mathrm{~A}$. In addition to high uptake in brain, image at 6 min shows high uptake in lungs and heart. Images at 50 and 102 min show excretion of radioactivity via liver, small bowel, and urinary bladder. These images were created by summing all coronal slices at each time point. Pixel values were decay-corrected to time of injection and displayed with same gray scale.
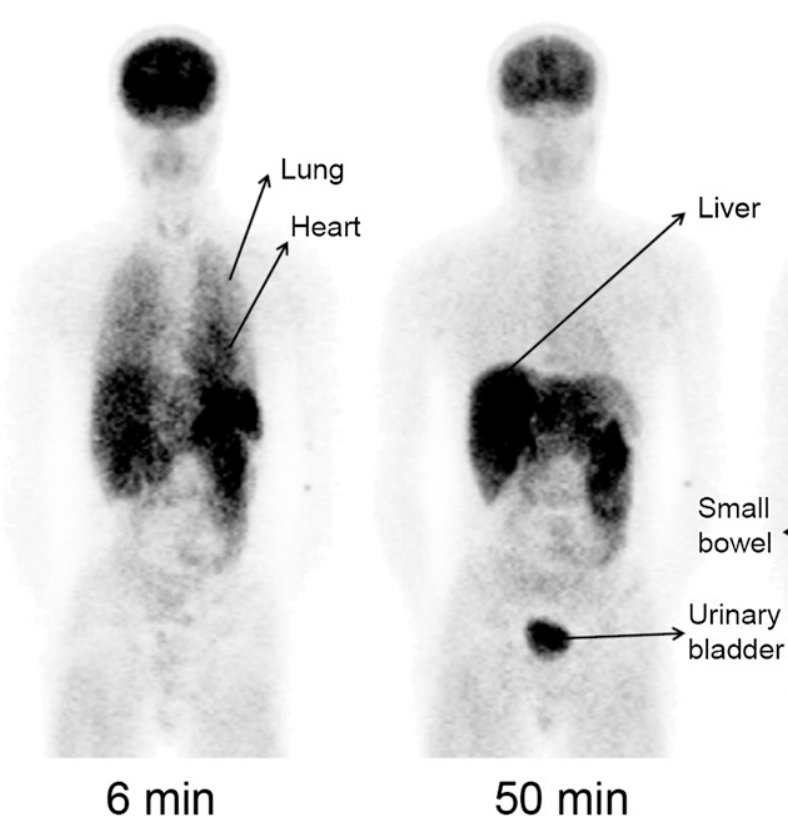

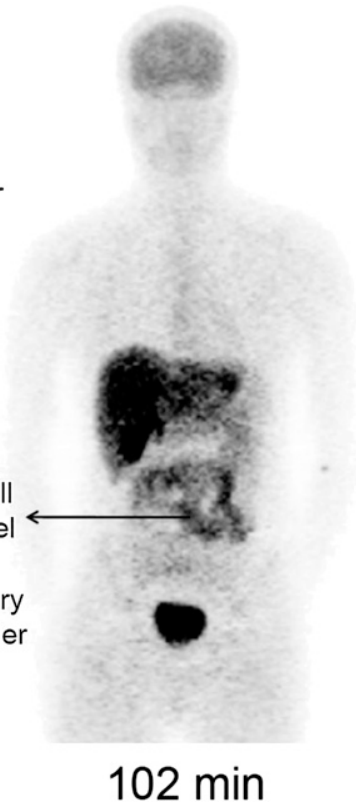



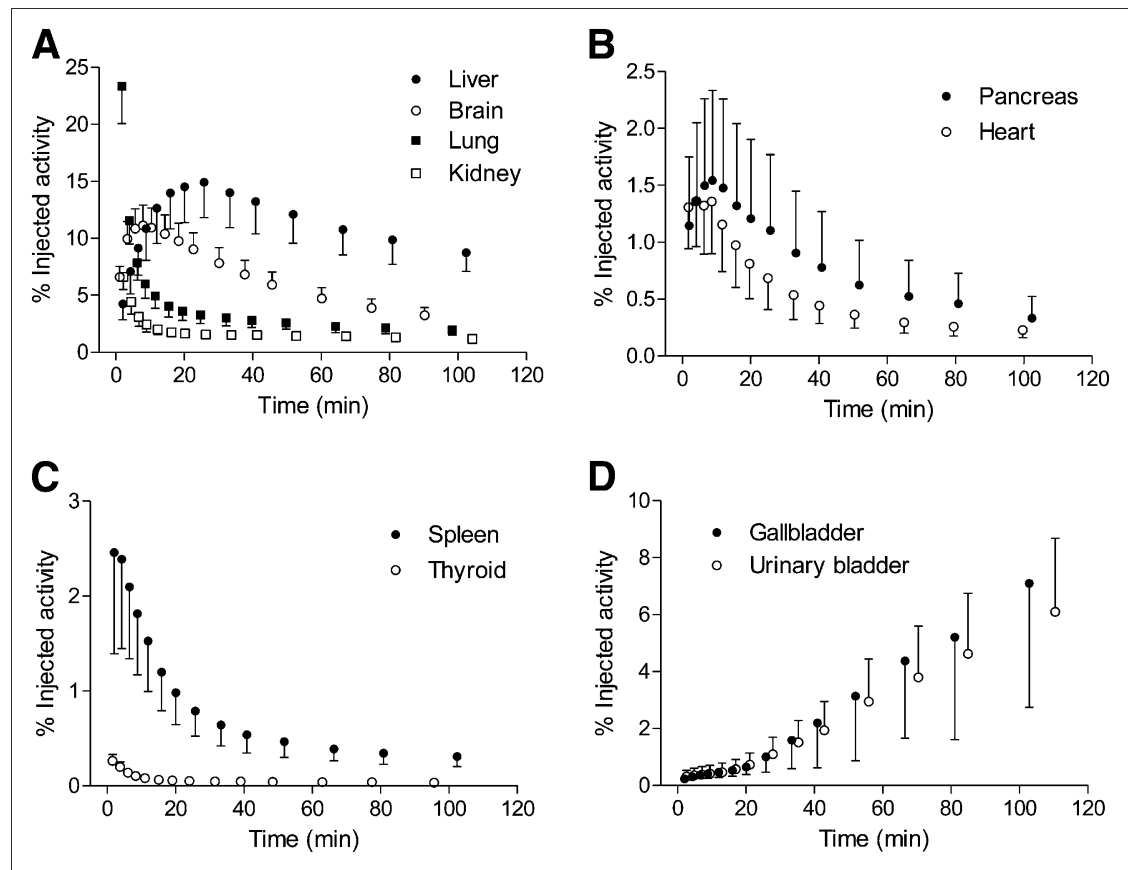

FIGURE 6. Time-activity curves for 10 source organs after ${ }^{11} \mathrm{C}-\mathrm{NOP}-1 \mathrm{~A}$ injection. Data are corrected for radioactive decay and expressed as mean and SD (symbol and error bars) from 9 subjects.

higher in monkeys than in humans. Changes in plasma free fraction between species can cause the difference in $V_{\mathrm{T}}$ values, but the plasma free fraction of ${ }^{11} \mathrm{C}-\mathrm{NOP}-1 \mathrm{~A}$ in monkeys $(11.3 \% \pm 1.1 \%(7))$ and humans $(10.1 \% \pm$ $1.7 \%$ [data from this study]) were similar. The sources of these differences are unclear, but possibilities include anesthesia, different proportions of gray and white matter, and different ratios of specific-to-nondisplaceable binding.

We further found that the Logan parametric method significantly underestimated $V_{\mathrm{T}}$ compared with the gold standard 2-tissue-compartment model, because the Logan method is vulnerable to low counts - and hence noise-in the imaging data. Despite a slight underestimation, $V_{\mathrm{T}}$ determined using the MA1 parametric method correlated well with that of the 2-tissue-compartment model, indicating that the MA1 parametric method measured ${ }^{11} \mathrm{C}-\mathrm{NOP}-1 \mathrm{~A}$ binding in brain in a manner comparable to the 2-tissuecompartment model. The small underestimate observed with the MA1 parametric method was significantly less than that observed with the Logan parametric method, specifically because the MA1 method reduces the magnitude of noise-induced bias compared with the Logan method (14). As a result, parametric methods such as MA1 can be used for SPM analyses to compare populations.

The effective dose of ${ }^{11} \mathrm{C}-\mathrm{NOP}-1 \mathrm{~A}(4.3 \mu \mathrm{Sv} / \mathrm{MBq})$ estimated from whole-body scans in humans was similar to previous estimates $(5 \mu \mathrm{Sv} / \mathrm{MBq})$ from monkey studies $(8)$ and to those of 34 other ${ }^{11} \mathrm{C}$-radioligands used for brain imaging, which ranged from 3 to $16 \mu \mathrm{Sv} / \mathrm{MBq}$ (19). The whole-body scans showed notable accumulation of radioactivity in peripheral organs such as heart, spleen, and pancreas. The radioactivity localization in these organs was confirmed by a PET/CT scan in a healthy subject (Supple- mental Fig. 5). NOP receptors are known to be present in human heart (20) and spleen, an organ rich in immune cells (21). Functional studies in exocrine pancreas of guinea pig indicated the presence of NOP receptors in pancreatic lobules (22). Thus, uptake in those organs may represent receptor-specific binding. Further research is necessary to verify NOP receptor-specific binding in peripheral organs.

${ }^{11} \mathrm{C}-\mathrm{NOP}-1 \mathrm{~A}$ has many positive attributes as a PET radioligand, including its short half-life of ${ }^{11} \mathrm{C}$ (20.4 min), which allows a subject to participate in 2 studies per day (e.g., to study treatment effects under identical conditions to reduce variability). Nevertheless, it also has at least 3 relative limitations. First, the short half-life of ${ }^{11} \mathrm{C}$ requires the availability of a cyclotron at the site of radioligand administration. Labeling with longerlived ${ }^{18} \mathrm{~F}$ (half-life, $109.7 \mathrm{~min}$ ) would be more useful, since that would allow central production and distribution to distant PET centers. Future developments in labeling radiotracers with nocarrier-added cyclotron-produced ${ }^{18} \mathrm{~F}$-fluoride ions, and in particular the use of diaryliodonium salts as precursors, might permit NOP-1A to be labeled in 1 step in its aryl fluoro position, thereby facilitating such applications $(23,24)$.

A second limitation of ${ }^{11} \mathrm{C}-\mathrm{NOP}-1 \mathrm{~A}$ is that a reference region in brain may not exist. ${ }^{11} \mathrm{C}-\mathrm{NOP}-1 \mathrm{~A}$ blockade studies in monkeys found that all regions of brain, including cerebellum - a low-binding region-had specific binding, suggesting a lack of reference region in brain. Displacement and blockade studies are needed in humans to assess whether this is also true in the larger human brain and to identify any reference region. Reference region identification would allow the use of image quantification by reference tissue models without invasive arterial blood sampling.

A third limitation is that because ${ }^{11} \mathrm{C}-\mathrm{NOP}-1 \mathrm{~A}$ is an antagonist, it is likely insensitive to displacement by the 
endogenous agonist of the NOP receptor. For example, ${ }^{11} \mathrm{C}$-carfentanil, a highly specific $\mu$-opioid receptor agonist, is displaced by endogenous opioids after a painful stimulus (25). Animal studies are needed to determine whether a significant proportion of NOP receptors is coupled to G-proteins or is even sensitive to agonists. For example, in the case of the $\mathrm{CB}_{1}$ receptor, most of the receptors appear to be in low affinity, G-protein-uncoupled states, thus making them unsuitable for binding with an agonist radioligand (26). In such cases, an antagonist such as ${ }^{11} \mathrm{C}-\mathrm{NOP}-1 \mathrm{~A}$ is favored over an agonist, given that an antagonist binds to the receptor with equal affinity and is not affected by the affinity status of the receptor.

\section{CONCLUSION}

Our results demonstrated that ${ }^{11} \mathrm{C}-\mathrm{NOP}-1 \mathrm{~A}$ reliably quantified NOP receptors in human brain both in large brain regions and at a voxelwise level using parametric imaging. The radiation absorbed dose in humans was similar to that observed with other ${ }^{11} \mathrm{C}$-labeled ligands and would allow multiple scans of a single subject. Thus, ${ }^{11} \mathrm{C}-\mathrm{NOP}-1 \mathrm{~A}$ is a promising radioligand for reliably quantifying NOP receptors in human brain. This, in turn, makes it a potential candidate to study the role of NOP receptors in disorders such as drug abuse and anxiety and to facilitate the development of therapeutic drugs at this target site.

\section{DISCLOSURE STATEMENT}

The costs of publication of this article were defrayed in part by the payment of page charges. Therefore, and solely to indicate this fact, this article is hereby marked "advertisement" in accordance with 18 USC section 1734.

\section{ACKNOWLEDGMENTS}

This study was supported by the Intramural Research Program of the National Institute of Mental Health, National Institutes of Health (IRP-NIMH-NIH), and by a Cooperative Research and Development Agreement with Eli Lilly \& Co. We thank Denise Rallis-Frutos, Gerald L. Hodges, Kimberly Jenko, David Clark, Jeih-San Liow, Robert L. Gladding, and the staff of the PET Department for assistance in successful completion of the studies, and PMOD Technologies (Zurich, Switzerland) for providing its image analysis and modeling software. Ioline Henter provided invaluable editorial assistance. No other potential conflict of interest relevant to this article was reported.

\section{REFERENCES}

1. Mollereau C, Parmentier M, Mailleux P, et al. ORL1, a novel member of the opioid receptor family: cloning, functional expression and localization. FEBS Lett. 1994;341:33-38.

2. Meunier JC, Mollereau C, Toll L, et al. Isolation and structure of the endogenous agonist of opioid receptor-like ORL1 receptor. Nature. 1995;377:532-535.
3. Lambert DG. The nociceptin/orphanin FQ receptor: a target with broad therapeutic potential. Nat Rev Drug Discov. 2008;7:694-710.

4. Economidou D, Hansson AC, Weiss F, et al. Dysregulation of nociceptin/orphanin FQ activity in the amygdala is linked to excessive alcohol drinking in the rat. Biol Psychiatry. 2008;64:211-218.

5. Varty GB, Hyde LA, Hodgson RA, et al. Characterization of the nociceptin receptor (ORL-1) agonist, Ro64-6198, in tests of anxiety across multiple species. Psychopharmacology (Berl). 2005;182:132-143.

6. Ciccocioppo R, Economidou D, Rimondini R, Sommer W, Massi M, Heilig M. Buprenorphine reduces alcohol drinking through activation of the nociceptin/ orphanin FQ-NOP receptor system. Biol Psychiatry. 2007;61:4-12.

7. Pike VW, Rash KS, Chen Z, et al. Synthesis and evaluation of radioligands for imaging brain nociceptin/orphanin FQ peptide (NOP) receptors with positron emission tomography. J Med Chem. 2011;54:2687-2700.

8. Kimura Y, Fujita M, Hong J, et al. Brain and whole-body imaging in rhesus monkeys of ${ }^{11} \mathrm{C}-\mathrm{NOP}-1 \mathrm{~A}$, a promising PET radioligand for nociceptin/orphanin FQ peptide receptors. J Nucl Med. 2011;52:1638-1645.

9. Gandelman MS, Baldwin RM, Zoghbi SS, Zea-Ponce Y, Innis RB. Evaluation of ultrafiltration for the free-fraction determination of single photon emission computed tomography (SPECT) radiotracers: beta-CIT, IBF, and iomazenil. J Pharm Sci. 1994;83:1014-1019.

10. Brown AK, Fujita M, Fujimura Y, et al. Radiation dosimetry and biodistribution in monkey and man of ${ }^{11} \mathrm{C}-\mathrm{PBR} 28$ : a PET radioligand to image inflammation. J Nucl Med. 2007;48:2072-2079.

11. Tzourio-Mazoyer N, Landeau B, Papathanassiou D, et al. Automated anatomical labeling of activations in SPM using a macroscopic anatomical parcellation of the MNI MRI single-subject brain. Neuroimage. 2002;15:273-289.

12. Innis RB, Cunningham VJ, Delforge J, et al. Consensus nomenclature for in vivo imaging of reversibly binding radioligands. J Cereb Blood Flow Metab. 2007;27: 1533-1539.

13. Logan J, Fowler JS, Volkow ND, et al. Graphical analysis of reversible radioligand binding from time-activity measurements applied to $\left[\mathrm{N}-{ }^{11} \mathrm{C}\right.$-methyl](-)-cocaine PET studies in human subjects. J Cereb Blood Flow Metab. 1990; 10:740-747.

14. Ichise M, Toyama H, Innis RB, Carson RE. Strategies to improve neuroreceptor parameter estimation by linear regression analysis. J Cereb Blood Flow Metab. 2002;22:1271-1281.

15. Fujita M, Seibyl JP, Verhoeff NP, et al. Kinetic and equilibrium analyses of [ $\left.{ }^{123} \mathrm{I}\right]$ epidepride binding to striatal and extrastriatal dopamine $\mathrm{D}_{2}$ receptors. Synapse. 1999;34:290-304.

16. Berthele A, Platzer S, Dworzak D, et al. $\left[{ }^{3} \mathrm{H}\right]$-nociceptin ligand-binding and nociceptin opioid receptor mrna expression in the human brain. Neuroscience. 2003;121:629-640.

17. Ogawa M, Hatano K, Kawasumi Y, et al. Synthesis and evaluation of 1-[(3R,4R)1-cyclooctylmethyl-3-hydroxymethyl-4-piperidyl]-3-[ $\left.{ }^{11} \mathrm{C}\right]$ ethyl-1,3-dihydro-2Hbenzimidazol-2-one as a brain ORL1 receptor imaging agent for positron emission tomography. Nucl Med Biol. 2003;30:51-59.

18. Ogawa M, Hatano K, Kawasumi Y, Wichmann J, Ito K. Synthesis and in vivo evaluation of $\left[{ }^{11} \mathrm{C}\right]$ methyl-Ro 64-6198 as an ORL1 receptor imaging agent. $\mathrm{Nucl}$ Med Biol. 2001;28:941-947.

19. Hines CS, Liow J-S, Zanotti-Fregonara P, et al. Human biodistribution and dosimetry of ${ }^{11} \mathrm{C}-\mathrm{CUMI}-101$, an agonist radioligand for serotonin-1A receptors in brain. PLOS ONE. 2011;6:e25309.

20. McDonald J, Leonard AD, Serrano-Gomez A, et al. Assessment of nociceptin/ orphanin FQ and micro-opioid receptor mRNA in the human right atrium. $\mathrm{Br} \mathrm{J}$ Anaesth. 2010;104:698-704.

21. Arjomand J, Cole S, Evans CJ. Novel orphanin FQ/nociceptin transcripts are expressed in human immune cells. J Neuroimmunol. 2002;130:100-108.

22. Linari G, Agostini S, Broccardo M, Petrella C, Improta G. Regulation of pancreatic secretion in vitro by nociceptin/orphanin FQ and opioid receptors: a comparative study. Pharmacol Res. 2006;54:356-360.

23. Cai LS, Lu SY, Pike VW. Chemistry with $\left[{ }^{18} \mathrm{~F}\right]$ fluoride ion. Eur J Org Chem. 2008;2853-2873.

24. Chun JH, Lu SY, Lee YS, Pike VW. Fast and high-yield microreactor syntheses of ortho-substituted $\left[{ }^{18} \mathrm{~F}\right]$ fluoroarenes from reactions of $\left[{ }^{18} \mathrm{~F}\right]$ fluoride ion with diaryliodonium salts. J Org Chem. 2010;75:3332-3338.

25. Bencherif B, Fuchs PN, Sheth R, Dannals RF, Campbell JN, Frost JJ. Pain activation of human supraspinal opioid pathways as demonstrated by $\left[{ }^{11} \mathrm{C}\right]$-carfentanil and positron emission tomography (PET). Pain. 2002;99:589-598.

26. Terry G, Liow JS, Chernet E, et al. Positron emission tomography imaging using an inverse agonist radioligand to assess cannabinoid CB1 receptors in rodents. Neuroimage. 2008;41:690-698. 